Williams Smith, H. (1953). J. gen. Microbiol. 8, 116-134.

\title{
The Effect of Physical and Chemical Changes on the Liberation of Phage Particles by Lysogenic Strains of Salmonella
}

\author{
BY H. WILLIAMS SMITH \\ The Animal Health Trust, Houghton Grange, Huntingdon
}

SUMMARY: Phage lysis was induced in lysogenic cultures of Salmonella by means of nitrogen mustard, mustard gas, sulphathiazole, glutathione, and sodium thiolacetate.

The liberation of phage particles by these cultures was inhibited by urethane, ascorbic acid, higher concentrations of thiolacetate than that necessary to induce lysis, and by incubating either at $41-43.5^{\circ}$ or at $\mathrm{pH} 5 \cdot 5$. Incubation at $22^{\circ}$ in some cases also had a slight inhibitory action.

The following substances had no effect on the liberation of phage particles by these cultures: penicillin, streptomycin, chloramphenicol, Proflavine, Rivanol, colchicine, methionine, cobalt sulphate, sodium citrate, brilliant green, sodium tetrathionate, sodium taurocholate, sodium biselenite, casein digest and yeast extracts. Cultivation either in atmospheres containing different amounts of oxygen, or at $28^{\circ}$, or in media containing varying concentrations of sodium chloride was also without effect.

Cultures did not become non-lysogenic as a result of prolonged passage in broth containing either sodium citrate, ascorbic acid or urethane.

In a previous paper (Williams Smith, 1951) observations were made on the liberation of phage particles by lysogenic strains of Salmonella thompson. These could be classified into two types, type 1 in which the number of free phage particles appeared to be directly related to the number of viable bacteria present in the culture, and type 2 in which the number of free phage particles increased more rapidly than the bacteria during the logarithmic phase of bacterial growth, decreased rapidly during a short period at the end of the logarithmic phase and then more slowly. These relations were quite stable when the conditions of experiment were constant. When lysogenic bacteria were actively infected with another phage an increased liberation of particles of the 'lysogenic' phage usually occurred. Since it is generally thought that phages exist within the bacterial cells of lysogenic cultures as non-infective units, I wondered whether active infection had altered the conditions within the bacterial cells permitting the phages to become infective, or whether the phages in these $S$. thompson cultures normally existed within the bacteria as infective units liberated by lysis produced by active infection. It seemed worth while to experiment to find out which was the case, and also to investigate other factors which influence the liberation of phage particles by lysogenic cultures of salmonellas.

That changes can be induced in the host-parasite relationship existing in lysogenic bacteria was first shown by Lwoff, Siminovitch \& Kjeldgaard (1950). Working with a lysogenic culture of Bacillus megaterium they found 
that exposure to ultraviolet light resulted in lysis of the culture with a great increase in the number of phage particles in the culture medium. This observation has been confirmed with other species of bacteria (Jacob, 1950; Cavallo \& Cantelmo, 1951; Lwoff \& Siminovitch, 1951; Quersin, 1951; Weigle \& Delbrück, 1951), although negative results have been obtained with some cultures (Bertani, 1951; Ionesco, 1952). A similar effect to that induced by ultraviolet light has been obtained with X-rays (Latarjet, 1951) and thermal shock (Cavallo, 1951). Phage lysis of lysogenic cultures of $B$. megaterium has also been induced by reducing agents (Lwoff et al. 1950; Lwoff \& Siminovitch, 1951).

\section{MATERIAL AND METHODS}

Basal medium. This consisted of heart broth containing $0.5 \%$ Oxoid peptone and $\mathbf{0 . 5} \%$ sodium chloride, $\mathrm{pH} \mathbf{7 \cdot 2}$.

Bacteria. Two of the $S$. thompson cultures had been used in previous experiments (Williams Smith, 1951); they are designated 19 (5/19) and $19(1 / 19)$ and are variants of strain 19 resistant to phage 5/19 and 1/19 respectively. Strain 19 was non-lysogenic and not resistant to any phages active on $S$. thompson.

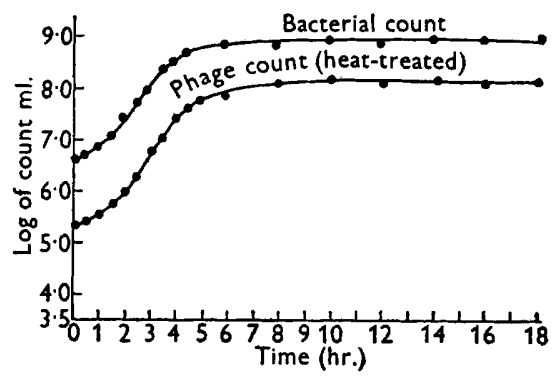

Fig. 1

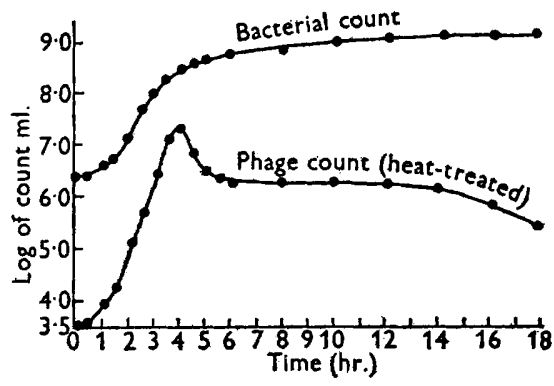

Fig. 2

Fig. 1. The growth rate of bacteria and phage in the lysogenic culture $19(5 / 19)$.

Fig. 2. The growth rate of bacteria and phage in the lysogenic culture $19(1 / 19)$.

The phage/bacterium growth curves of these two strains, which are essentially dissimilar, are illustrated in Figs. 1 and 2. The other lysogenic strains used were naturally occurring ones; these $S$. thompson strains were designated 2, 3, 8 and 11. All six $S$. thompson strains differed from each other either by carrying different phages, or by carrying more than one phage. One of the $S$. cholerae-suis strains was of the kunzendorf variety (C11) and the other was the classical species (C16). The $S$. typhimurium strains (M1 and M2) carried different phages.

Bacterial counts. All experiments were carried out in the glass cells of a photo-electric absorptiometer so that the bacterial content could be estimated at any stage of the growth cycle of a culture. However, since it was thought that there might be variation in the size of the bacterial cells, some direct bacterial counts by the method of Miles \& Misra (1938) were made in every experiment. 
Phage counts. A modification of the Miles \& Misra (1938) method for bacterial counts was used for this purpose (Williams Smith, 1951). Nutrient agar $(2 \%)$ plates were dried for $24 \mathrm{hr}$. at $37^{\circ}$ followed by a further $2 \mathrm{hr}$. with the lids raised. Four drops $(0.08 \mathrm{ml}$.) of an $18 \mathrm{hr}$. broth culture of a susceptible strain were spread evenly over the surface of these plates, and drying was continued for another hour with the lids raised. The procedure then adopted was exactly that for bacterial counts. The plates were incubated at $37^{\circ}$ for $18 \mathrm{hr}$. before plaque counts were made.

All lysogenic cultures were heated to $56^{\circ}$ for $30 \mathrm{~min}$. referred to as heat treatment, before estimating their content of free phage.

Non-lysogenic strains were used for determining phage counts, strain 19 for $S$. thompson phages, C15 for $S$. cholerae-suis phages, M11 for $S$. typhimurium phages.

Method of carrying out tests. The effects were studied in detail only on the artificially prepared lysogenic $S$. thompson strains $19(5 / 19)$ and $19(1 / 19)$. When a chemical effect was studied varying amounts of the chemical were added to $5 \mathrm{ml}$. of broth contained in absorptiometer cells. This was inoculated usually with $0.02 \mathrm{ml}$. of $1 / 200$ dilution of an overnight broth culture of the lysogenic strain. The cultures were incubated at $37^{\circ}, 0.1 \mathrm{ml}$. removed at suitable intervals, and its phage content determined. Similar amounts were removed for viable bacterial counts. Phage and bacterial counts on control cultures consisting of the same bacterial strain growing in the basal medium alone were carried out at the same time. Control experiments were also carried out to determine whether the chemical or physical effect under study had any action on free phage particles; reference is made to this type of control in the text only in the mustards since none of the other chemical or physical effects had any observable effect on free phage particles.

The experiments were then repeated with the other lysogenic strains of $S$. thompson, and the $S$. cholerae-suis and $S$. typhimurium strains, but phage and bacterial counts were made only at two stages during the growth cycle.

Some of the chemicals studied caused changes in the medium, as $\mathrm{pH}$ value, which were largely incidental to the effect being studied. When possible these incidental changes were corrected and, when possible, the chemical changes being studied were neutralized in the portions of culture medium removed for phage counting.

Growth curves. Many of the results obtained with cultures 19 (5/19) and $19(1 / 19)$ are illustrated by plotting the phage counts against the bacterial counts at different points in the growth cycle. This method has the great advantage of simplicity. Attempts to plot bacterial and phage counts against time of incubation were complicated by effects on the rate of bacterial growth. The time intervals at which counts were carried out were usually farther apart than those shown in Fig. 2, so that the peak of phage production near the end of the logarithmic phase of $19(1 / 19)$ was not always noted.

Cyanide lysis. This was carried out by a modification of Doermann's technique (Rountree, 1951). Overnight broth cultures of lysogenic strains in $10 \mathrm{ml}$. amounts were centrifuged. The supernatant containing most of the free 
phage was discarded and the deposited bacteria resuspended in $2 \mathrm{ml}$. of sterile distilled water. One half of this was retained at $5^{\circ}$ to serve as a control and $0.1 \mathrm{ml}$. of $\mathbf{0} \cdot \mathbf{2} \mathrm{M}$-sodium cyanide added to the other. This was subjected to alternate freezing and thawing until the majority of the bacterial cells had lysed; phage counts were then made. Similar experiments were carried out on the phages carried by the lysogenic strains to determine whether the experimental procedure had any effect on free phage.

The expressions 'lysogenic', 'carrying phage', and 'latently infected with phage' are used synonymously.

\section{RESULTS}

The accuracy of the method of counting phage particles

The average of twenty separate counts of the free phage in a culture of $19(5 / 19)$ was $153 \times 10^{4}$ phage particles per ml. with a variation of $+13 \%$ and $-15 \%$.

\section{Cyanide lysis}

Cyanide lysis did not result in the liberation of infective phage particles by cultures of the two lysogenic strains 19 (5/19) and $19(1 / 19)$.

\section{The effect of incubation temperature}

Growth curves showing the relationship of free phage particles to the number of bacteria in cultures of $19(5 / 19)$ and $19(1 / 19)$ incubated at different temperatures are shown in Fig. 3. No increase in the number of free phage particles in $19(5 / 19)$ was noted at any stage in the growth cycle when incuba-

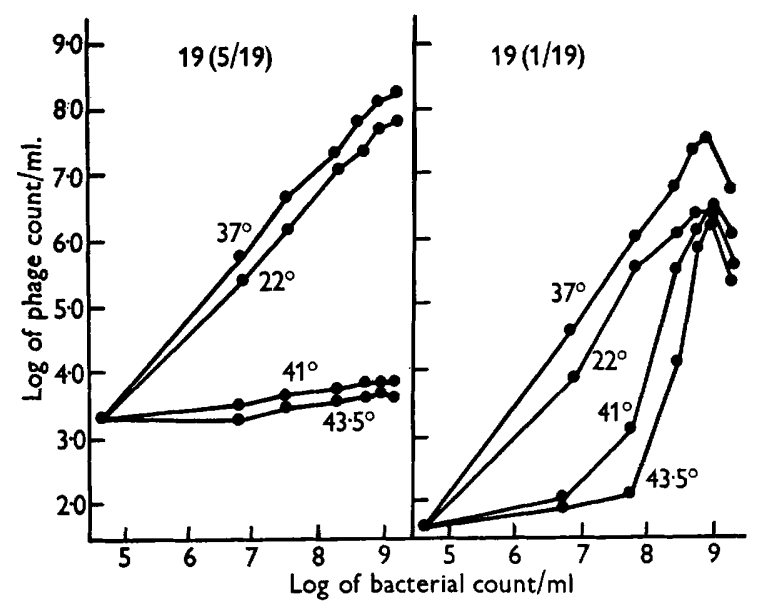

Fig. 3. The effect of incubation temperature on the liberation of phage particles by cultures of $19(5 / 19)$ and $19(1 / 19)$.

tion was carried out at 41 and $43 \cdot 5^{\circ}$. Very little increase was noted at these temperatures in $19(1 / 19)$ until towards the end of the logarithmic phase when the count increased considerably but not to the level of cultures at $37^{\circ}$. Passage of $19(1 / 19)$ at $43 \cdot 5^{\circ}$ showed a similar curve on each occasion. The 
liberation of phage particles was slightly inhibited in both $19(5 / 19)$ and $19(1 / 19)$ when they were incubated at $22^{\circ}$; there was no difference between the results for temperatures of 28 and $37^{\circ}$.

Somewhat similar results were obtained with the naturally occurring lysogenic strains. The results for incubation at $43 \cdot 5^{\circ}$ resembled those for $19(5 / 19)$ more closely than those for $19(1 / 19)$. Greater inhibition of phage liberation was noted at $22^{\circ}$ than with $19(5 / 19)$ and $19(1 / 19)$.

Strains $19(5 / 19), 2, \mathrm{C} 11$, and C16 were passaged through broth at $43 \cdot 5^{\circ}$ seven times. They were still lysogenic at the final transfer and were liberating little or no free phage.

\section{The effect of hydrogen-ion concentration}

Cultures of $19(5 / 19)$ and $19(1 / 19)$ were grown in the basal broth at $\mathrm{pH} 5.5$, $7 \cdot 2$ and $9 \cdot 0$; only at pH $5 \cdot 5$ was any difference noted in the yield of free phage particles (Fig. 4). No difference was noted when the experiment was repeated at $\mathrm{pH} 6.2$. In $19(5 / 19)$ the yield of free phage at $\mathrm{pH} 5.5$ at all stages in the growth cycle was approximately 100 times less than at $\mathrm{pH} 7 \cdot 2$. Even greater inhibition was noted in the case of $19(1 / 19)$, little phage liberation occurring at $\mathrm{pH} 5 \cdot 5$.

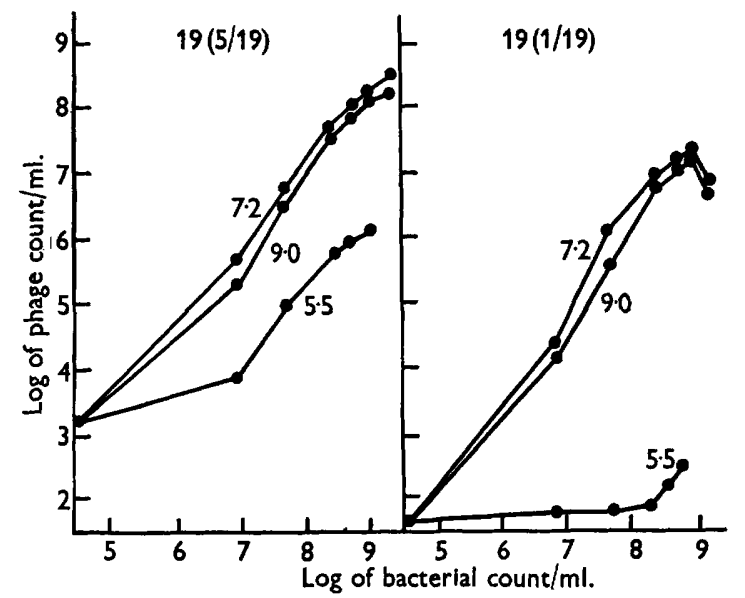

Fig. 4. The effect of $\mathrm{pH}$ of the medium on the liberation of phage particles by cultures of $19(5 / 19)$ and $19(1 / 19)$.

The results with five other cultures also showed inhibition of phage production to occur at $\mathrm{pH} 5 \cdot 5$, the degree of inhibition varying with the culture under test. No phage liberation was detected in one $S$. typhimurium culture at this $\mathrm{pH}$.

When strains $19(5 / 19)$ and $19(1 / 19)$ were passaged three times through broth at $\mathrm{pH} \mathrm{5.5}$ a similar bacterial/free phage growth curve was obtained on each occasion; when passaged strains were then grown in broth at $\mathrm{pH} \mathbf{7 \cdot 2}$, a normal $\mathrm{pH} 7 \cdot 2$ growth curve was obtained showing, as in the case of passage at $43 \cdot 5^{\circ}$, that there was no evidence of adaptation occurring. 


\section{The effect of aeration}

Bacterium/free phage growth curves of aerated $19(5 / 19)$ and $19(1 / 19)$ were identical with those of control cultures. Aeration had no effect in preventing the phage absorption that occurs at the end of the logarithmic phase of growth of $19(1 / 19)$.

\section{Anaerobic cultivation}

When strains $19(5 / 19), 19(1 / 19), 2,3,8,11, \mathrm{C} 11$, and $\mathrm{C} 16$ were grown in the anaerobic atmosphere obtainable in a McIntosh and Fildes jar the amount of free phage liberated was the same as that liberated by control cultures grown in air.

\section{Sodium thiolacetate}

The effect of different concentrations of sodium thiolacetate on the liberation of phage particles by $19(5 / 19)$ and $19(1 / 19)$ is shown in Table 1 . A great increase in phage particles was noted with concentrations of sodium thiolacetate of between 0.0125 and $0.1 \%$, the highest yield occurring when the concentration was $0.05 \%$; concentrations above $0.1 \%$ had an inhibitory effect on free phage production.

Table 1. The effect of different concentrations of sodium thiolacetate on the liberation of phage particles by cultures of 19 (5/19) and $19(1 / 19)$

At the beginning of the experiment $19(5 / 19)$ contained $12.5 \times 10^{4}$ bacteria $/ \mathrm{ml}$. and $10^{4}$ phage particles $/ \mathrm{ml}$. and $19(1 / 19)$ contained $120 \times 10^{3}$ bacteria $/ \mathrm{ml}$. and $10^{3}$ phage particles $/ \mathrm{ml}$.

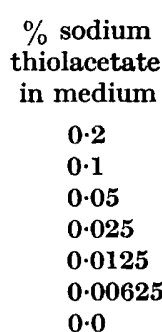

$\begin{array}{cc}\begin{array}{c}\text { Phage particles, } 10^{4} / \mathrm{ml}^{\mathrm{m}}, \text { liberated at approx. } \\ \text { bacterial count of } 10^{8} \text { bacteria/ml. of }\end{array} \\ \overbrace{19(5 / 19)}^{19(1 / 19)} \\ 15 & 25 \\ 2,500 & 5,000 \\ 250,000 & 150,000 \\ 32,000 & 30,000 \\ 5,000 & 2,000 \\ 1,800 & 350 \\ 1,550 & 350\end{array}$

Growth curves of $19(5 / 19)$ and $19(1 / 19)$ grown in broth containing $0 \cdot 2$ and $0.05 \%$ thiolacetate are shown in Fig. 5. Both cultures in $0.05 \%$ thiolacetate broth showed very large increases in the numbers of free particles, particularly in the earlier stages of bacterial growth, the amount of free phage liberated then being about 1000 or more times that found in control cultures. No actual clearing of the broth was noted at this stage but bacterial growth either ceased for a time or proceeded more slowly than in a control. It was difficult to make comparisons on a time basis since thiolacetate normally had a depressant action on the bacterial growth rate. Phage lysis was also induced in the early stages of bacterial growth in media containing $0.2 \%$ thiolacetate. Later, however, this concentration inhibited phage production 
and the count decreased, presumably due to bacterial absorption as thiolacetate did not have a lethal action on free phage particles. The process of phage production and absorption fluctuated as shown by the irregularity of the phage/bacterial growth curves.

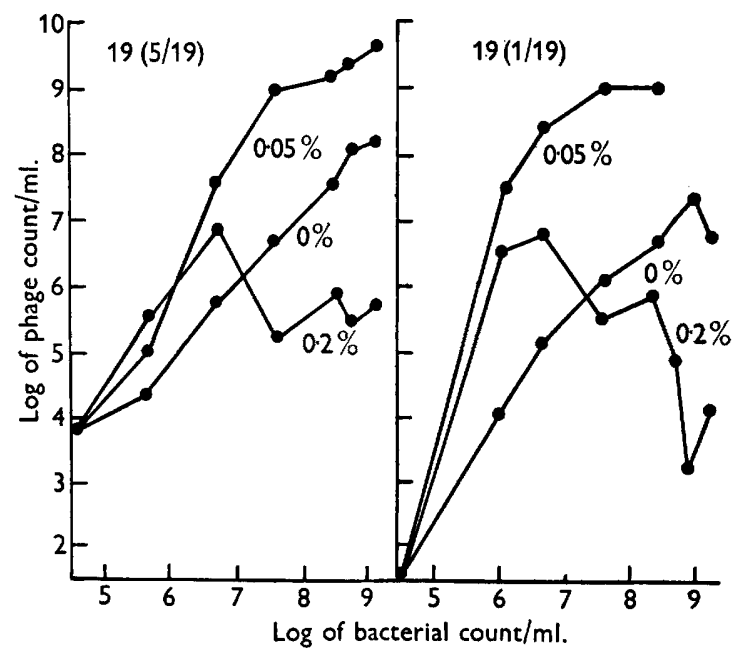

Fig. 5. The effect of the addition of sodium thiolacetate to the medium on the liberation of phage particles by cultures of $19(5 / 19)$ and $19(1 / 19)$.

The results obtained with $19(5 / 19)$ and $19(1 / 19)$ could be repeated at will, and passage of cultures through broth containing thiolacetate showed the same type of free phage/bacterium relation on each occasion. Different concentrations might be required to produce the same effect when different batches of broth were used. The results were also applicable to the naturally occurring lysogenic strains.

In view of Lwoff's (1952) work strain 19 (1/19) was grown in broth containing $0.0005 \%$ copper sulphate and different concentrations of sodium thiolacetate, and in a similar series of thiolacetate concentrations with the copper sulphate replaced by $0.0005 \%$ cobalt sulphate. The results (Table 2 ) showed that the yields of free phage at each concentration of thiolacetate were the same whether or not copper and cobalt were added.

Table 2. The effect of copper and cobalt on the liberation of phage particles by strain $19(1 / 19)$

The culture at the beginning of the experiment contained $25 \times 10^{4}$ bacteria $/ \mathrm{ml}$. and $10^{3}$ free phage particles $/ \mathrm{ml}$.

Phage particles $10^{4} / \mathrm{ml}$, liberated at a bacterial count of
$70 \times 10^{8} / \mathrm{ml}$. in media containing sodium thiolacetate in concentrations of

\begin{tabular}{|c|c|c|c|c|c|c|}
\hline Media & $0 \%$ & $0.001 \%$ & $0.0033 \%$ & $0.01 \%$ & $0.033 \%$ & $0 \cdot 1 \%$ \\
\hline Broth & $360 \cdot 0$ & $350 \cdot 0$ & $250 \cdot 0$ & $350 \cdot 0$ & $200,000 \cdot 0$ & $750 \cdot 0$ \\
\hline Broth $+0.0005 \% \mathrm{CuSO}_{4}$ & $300 \cdot 0$ & $320 \cdot 0$ & $350 \cdot 0$ & $370 \cdot 0$ & $175,000 \cdot 0$ & $500 \cdot 0$ \\
\hline Broth $+0.0005 \% \mathrm{CoSO}_{4}$ & $280 \cdot 0$ & $200 \cdot 0$ & $180 \cdot 0$ & $350 \cdot 0$ & $150,000 \cdot 0$ & $600 \cdot 0$ \\
\hline
\end{tabular}


The results of some experiments to elucidate the action of thiolacetate are illustrated in Tables 3 and 4 . These consisted of estimating the amount of free phage in cultures of $19(1 / 19)$ in broth containing different amounts of thiolacetate. One culture was aerated, another was in an anaerobic atmosphere and the third had a seal of liquid paraffin. Phage production by means of

Table 3. The effect of the oxidation/reduction conditions on the induction of phage lysis in a culture of $19(1 / 19)$ by thiolacetate. (I) The effect of aeration and anaerobiosis

The culture at the beginning of the experiment contained $25 \times 10^{3}$ bacteria $/ \mathrm{ml}$. and $10^{2}$ free phage particles $/ \mathrm{ml}$.

\begin{tabular}{|c|c|c|c|}
\hline \multirow{2}{*}{$\begin{array}{c}\% \\
\text { sodium } \\
\text { thiolacetate } \\
\text { in medium }\end{array}$} & \multicolumn{3}{|c|}{$\begin{array}{l}\text { Phage particles, } 10^{4} / \mathrm{ml} \text {., liberated at bacterial count } \\
\qquad \text { of } 40 \times 10^{6} / \mathrm{ml} \text {. during }\end{array}$} \\
\hline & Aeration & $\begin{array}{l}\text { Normal } \\
\text { conditions }\end{array}$ & Anaerobiosis* \\
\hline $0 \cdot 2$ & 5,000 & 400 & n.t. \\
\hline $0 \cdot 1$ & 1,000 & 5,000 & $2 \cdot 5$ \\
\hline 0.04 & 500 & 40,000 & 100 \\
\hline 0.02 & 40 & 10,000 & 240 \\
\hline 0 & 200 & 180 & 150 \\
\hline
\end{tabular}

* Incubated in McIntosh \& Fildes jar. n.t. = not tested.

Table 4. The effect of the oxidation/reduction conditions on the induction of phage lysis in a culture of 19 (1/19) by thiolacetate. (II) The effect of a liquid paraffin seal

The culture at the beginning of the experiment contained $25 \times 10^{3}$ bacteria $/ \mathrm{ml}$. and $10^{2}$ free phage particles $/ \mathrm{ml}$.

\begin{tabular}{|c|c|c|c|c|}
\hline \multirow{3}{*}{$\begin{array}{c}\% \\
\text { sodium } \\
\text { thiolacetate } \\
\text { in medium }\end{array}$} & \multicolumn{4}{|c|}{ Phage particles, $10^{4} / \mathrm{ml}$, liberated at bacterial count of } \\
\hline & \multicolumn{2}{|c|}{$20 \times 10^{6}$} & \multicolumn{2}{|c|}{$1000 \times 10^{6}$} \\
\hline & Seal & No seal & Seal & No seal \\
\hline $0 \cdot 2$ & 150 & 500 & 0 & $0 \cdot 3$ \\
\hline 0.1 & 2,000 & 25,000 & 5 & 50 \\
\hline 0.05 & 60,000 & 50,000 & 175 & 1,500 \\
\hline 0.025 & 20,000 & $\mathbf{3 0 , 0 0 0}$ & 1,250 & 12,000 \\
\hline 0.0125 & 300 & 350 & 1,750 & 3,000 \\
\hline $\mathbf{0}$ & 90 & 75 & 400 & 600 \\
\hline
\end{tabular}

thiolacetate could not be obtained in the anaerobic atmosphere. Only a slight increase in the number of free phage particles was noted in aerated cultures, and then only in broth containing higher concentrations of thiolacetate than induced phage in the control cultures, in fact in concentrations that were inhibitory in controls (Table 3). Bacterial and phage counts were made at two stages in the growth cycle in the paraffin-sealed culture. The results (Table 4) showed that inhibition of phage production, and phage absorption, occurred with lower concentrations of thiolacetate in the paraffinsealed culture than in the control. 


\section{Glutathione}

The addition of glutathione to the basal broth induced phage lysis in cultures of $19(5 / 19)$ and $19(1 / 19)$ in a manner closely resembling that produced by thioglycollate, although the effect was not so marked. The most active concentration of glutathione was $0.05 \%$.

\section{Glucose and iron strips}

Growth curves of $19(5 / 19)$ and $19(1 / 19)$ cultivated in basal broth containing different concentrations of glucose and strips of metallic iron closely resembled those obtained in basal broth alone.

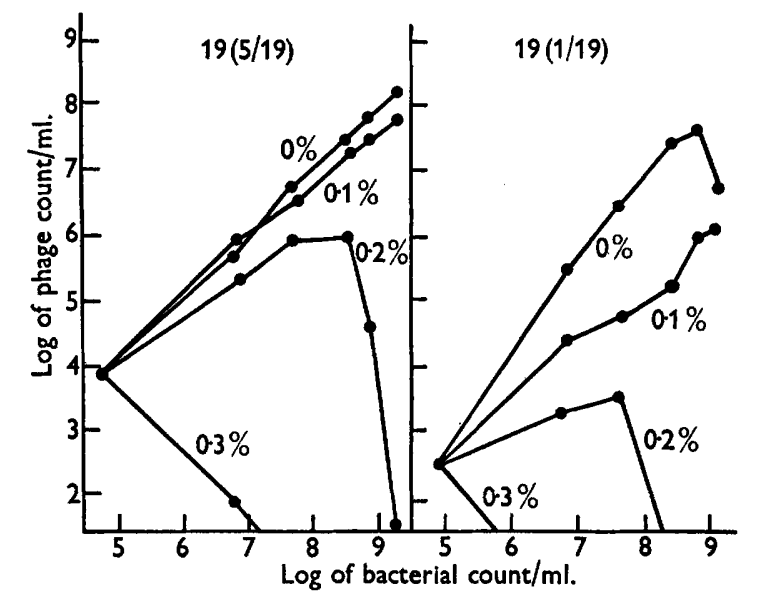

Fig. 6. The effect of the addition of ascorbic acid to the medium on the liberation of phage particles by cultures of $19(5 / 19)$ and $19(1 / 19)$.

\section{Ascorbic acid}

Growth curves of $19(5 / 19)$ and $19(1 / 19)$ cultivated in broth containing $\mathbf{0} \cdot 3,0 \cdot 2,0 \cdot 1$ and $0 \%$ ascorbic acid are shown in Fig. 6. Concentrations of $0 \cdot 1-0.3 \%$ ascorbic acid had an inhibitory effect on phage production, this effect, aided presumably by bacterial absorption of the free phage particles, being much more noticeable towards the end of the growth cycle, no free phage being demonstrable in cultures grown in 0.2 and $0.3 \%$ ascorbic acid at the end of the cycle. This inhibition was not related to the low $\mathrm{pH}$ produced by the higher concentrations of ascorbic acid since acidity was corrected before each experiment. Concentrations below $0 \cdot 1 \%$ had no effect on phage liberation. Repeated attempts to induce phage lysis by ascorbic acid in a similar manner to thioglycollate were consistently negative. The addition of $0.0005 \%$ copper sulphate to the medium had no effect on the action of ascorbic acid.

The results with other salmonellas were 'similar to those with $19(5 / 19)$ and $19(1 / 19)$, marked inhibition of phage liberation occurring with concentrations of 0.3 and $0.2 \%$ ascorbic acid and yields similar to those of control 
cultures with lower concentrations of ascorbic acid. Strains $19(5 / 19)$ and 8 were passaged through broth containing $0 \cdot 3 \%$ ascorbic acid, each passage taking $10 \mathrm{hr}$. Single colonies obtained by plating out these cultures after fifty passages were lysogenic.

\section{The effect of sodium chloride concentration}

Sodium chloride in final concentrations of $0.5,1 \cdot 0,2 \cdot 0,4.0$ and $6.0 \%$ was added to salt-free broth. With strains $19(5 / 19)$ and $19(1 / 19)$ the yield of free phage was the same irrespective of the sodium chloride concentration. Growth curves of $19(5 / 19)$ and $19(1 / 19)$ in broth containing $0,0.5$ and $4 \%$ added sodium chloride were identical as regards phage liberation.

\section{Penicillin}

As regards the free phage/bacterium ratio, growth curves of $19(5 / 19)$ and $19(1 / 19)$ in broth containing 8,10 and $12 \mathrm{u} . / \mathrm{ml}$. of penicillin, concentrations which permitted considerable bacterial growth before penicillin lysis took place, were no different from those of controls up to the time when penicillin lysis occurred. Phage counts at different times after penicillin lysis were the same as those before lysis. It was not possible to obtain reliable direct bacterial counts of the broth cultures containing penicillin so, unlike all the other experiments, complete reliance was placed on absorptiometer readings.

The addition of smaller amounts of penicillin to $19(5 / 19)$ and $19(1 / 19)$ so that the bacterial growth rate decreased but no visible penicillin lysis occurred had no effect on the liberation of phage particles.

Phage 5/19 was unaffected by incubation at $37^{\circ}$ for $24 \mathrm{hr}$. in broth containing $1000 \mathrm{u}$. penicillin $/ \mathrm{ml}$.

\section{Streptomycin}

Streptomycin in final concentrations of 3-4.5 $\mathrm{g}$. $/ \mathrm{ml}$. was sufficient to cause a marked decrease in the growth rate of $19(5 / 19)$ and $19(1 / 19)$, but was without effect on the liberation of phage particles; the free phage/bacterium ratios closely resembled those of control cultures.

Phage 5/19 was unaffected by incubation at $37^{\circ}$ for $24 \mathrm{hr}$. in broth containing $1 \mathrm{mg}$. streptomycin $/ \mathrm{ml}$.

\section{Chloramphenicol}

The free phage/bacterium ratio of $19(5 / 19)$ and $19(1 / 19)$ grown in broth containing 1-25-3 $\mu \mathrm{g}$. chloramphenicol $/ \mathrm{ml}$, , concentrations sufficient to cause a marked decrease in bacterial growth rate, closely resembled those of control cultures. Phage 5/19 was unaffected by incubation at $37^{\circ}$ for $24 \mathrm{hr}$. in broth containing $1 \mathrm{mg}$. chloramphenicol $/ \mathrm{ml}$.

\section{Sulphathiazole}

The effect of the addition of sulphathiazole to the medium on the liberation of free phage particles by cultures $19(5 / 19)$ and $19(1 / 19)$ is illustrated in Fig. 7 which shows that sulphathiazole stimulated phage production so that 
at some stages the culture contained 10-500 times that present in control cultures. These experiments were repeated with different concentrations of sulphathiazole and different amounts of bacterial inoculum. The results showed that the amount of free phage liberated was not necessarily directly related to the concentration of sulphathiazole but was dependent on the ability of sulphathiazole to decrease the bacterial growth rate. For example, when broth containing 10 and $100 \mathrm{mg}$. sulphathiazole/ml. was used (i.e.

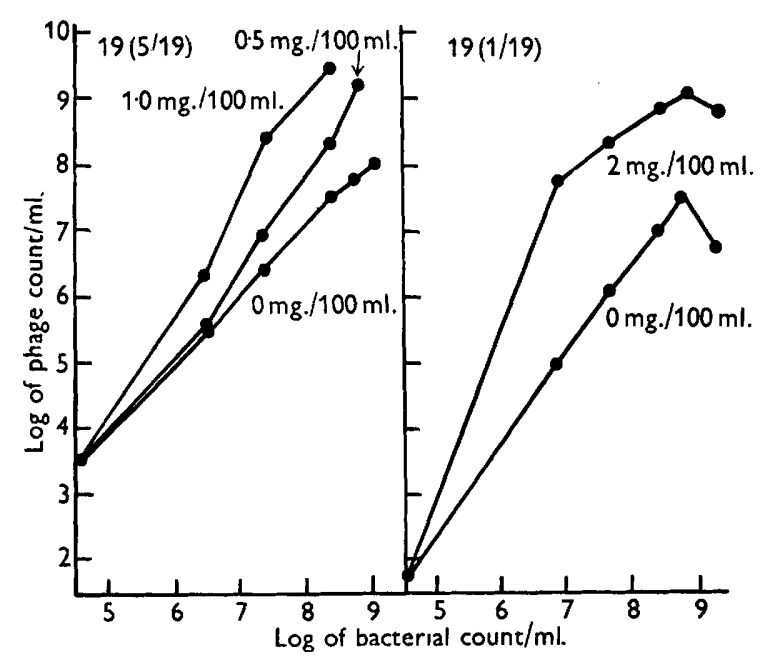

Fig. 7. The effect of the addition of sulphathiazole to the medium on the liberation of phage particles by cultures of $19(5 / 19)$ and $19(1 / 19)$

concentrations that partially or completely inhibited bacterial growth from the usual small inoculum) and the initial inoculum was sufficiently large to avoid inhibition of the bacterial growth rate, the bacterium/free phage ratio was similar to that of control cultures. Similarly, when the bacteriostatic effect of sulphathiazole was counteracted by $p$-aminobenzoic acid and the usual small inoculum used a normal bacterial/free phage ratio resulted.

When cultures of $19(5 / 19)$ and $19(1 / 19)$ that had been subjected to sulphathiazole were subcultured in the basal broth normal bacterium/free phage ratios were noted showing that sulphathiazole induction was not due to selection of a lytic population of bacteria. Similar results were obtained when sulphamezathine was used instead of sulphathiazole. When the naturally occurring lysogenic salmonellas were grown in basal broth containing sufficient sulphathiazole to decrease the growth rate a considerable increase in free phage usually occurred, although with two strains of $S$. thompson, 2 and 3 , no increase was noted and with one of the two strains of $S$. typhimurium the increase was slight. 


\section{Proflavine and Rivanol}

The addition to the basal broth of $0.00025-0.002 \%$ Proflavine and 0.00025-0.001\% Rivanol had no effect on the liberation of phage particles by $19(5 / 19)$ and $19(1 / 19)$. The higher concentrations were sufficient to decrease the growth rate of both strains.

\section{Nitrogen mustard (di(2-chloroethyl)methylamine)}

Preliminary experiments ('Table 5) showed that the addition of nitrogen mustard in concentrations of $0 \cdot 1-0.2 \mathrm{mg} . / \mathrm{ml}$. to the basal broth resulted in an increased liberation of phage particles by $19(1 / 19)$. When 0.6 and $0.8 \mathrm{mg} . / \mathrm{ml}$. were used no free phage was detected; bacterial growth occurred although, as in the lower concentrations, the growth rate was decreased. Phages 5/19 and $1 / 19$ carried by strains $19(5 / 19)$ and $19(1 / 19)$ were added to broth containing $0.8 \mathrm{mg} . / \mathrm{ml}$. of nitrogen mustard and incubated for $1 \mathrm{hr}$. at $37^{\circ}$. Tests showed that ail the phage particles were destroyed, and this lethal effect accounted for the absence of free phage particles in broth containing the higher concentrations of nitrogen mustard.

\section{Table 5. The effect of different concentrations of nitrogen mustard} on the liberation of free phage particles by strain $19(1 / 19)$

Each culture at the beginning of the experiment contained $c .60 \times 10^{3}$ bacteria $/ \mathrm{ml}$. and $10^{3}$ phage particles $/ \mathrm{ml}$.

\begin{tabular}{|c|}
\hline $\begin{array}{l}\text { Concentration } \\
\text { of nitrogen } \\
\text { mustard } \\
(\mathrm{mg} \cdot / \mathrm{ml} .)\end{array}$ \\
\hline 0 \\
\hline $0 \cdot 1$ \\
\hline 0.2 \\
\hline 0.4 \\
\hline 0.6 \\
\hline 0.8 \\
\hline
\end{tabular}

Free phage particles,
$\times 10^{4} /$ ml., liberated at
approx. bacterial count
of $300 \times 10^{8}$
1,250
30,000
10,000
1,200
0
0

The effect of growing $19(5 / 19)$ and $19(1 / 19)$ in broth containing $0 \cdot 15 \mathrm{mg}$. nitrogen mustard $/ \mathrm{ml}$. is shown in Fig. 8 . This shows that at practically all stages in the growth cycle the increase in the liberation of phage particles was between 10 and 100 times greater than that of control cultures. The results of growing other lysogenic salmonellas in broth containing $0.15 \mathrm{mg}$. nitrogen mustard $/ \mathrm{ml}$. showed that in all but one (C16) of the eight cultures a similar increase in the liberation of phage particles occurred.

An alternative method that resulted in a much greater liberation of phage particles was to incubate a culture containing approximately $50 \times 10^{6}$ bacteria $/ \mathrm{ml}$. and $0.8 \mathrm{mg}$. nitrogen mustard $/ \mathrm{ml}$. for $\frac{1}{2} \mathrm{hr}$. at $37^{\circ}$. All the free phage was destroyed but the viable bacterial count was unaltered. The culture was centrifuged, the supernatant fluid poured off and the deposit of bacteria mixed with basal broth to the original volume of the culture. This was then 
incubated at $37^{\circ}$, together with a control culture not exposed to nitrogen mustard. For a varying time, sometimes up to $2 \mathrm{hr}$., bacterial growth proceeded at a similar rate in the experimental and control cultures and the same free phage/bacterium ratio existed in each. Growth then ceased in the experimental culture and clearing started. Phage counts carried out during the clearing period showed a great and rapid increase in the number of free phage

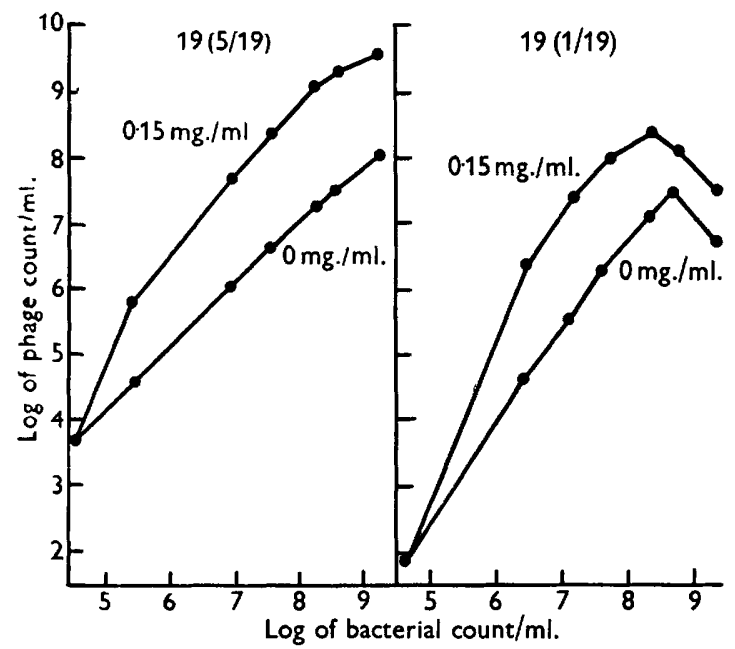

Fig. 8. The effect of the addition of nitrogen mustard to the medium on the liberation of phage particles by cultures of $19(5 / 19)$ and $19(1 / 19)$.

particles. For example, a culture of $19(5 / 19)$ contained $30 \times 10^{6}$ free phage particles/ml. at the stage when bacterial growth ceased and clearing began. Approximately $45 \mathrm{~min}$. later the phage count was $45 \times 10^{9}$ free phage particles $/ \mathrm{ml}$. The amount of clearing that occurred varied, but it was never complete. After the stage of clearing, bacterial growth again took place. The results obtained with eight lysogenic cultures are shown in Table 6. In seven very great increases in the liberation of phage particles occurred, but in one, $19(1 / 19)$, despite repeated attempts, it was impossible to induce phage lysis by this method.

\section{Mustard gas}

Experiments with mustard gas were carried out with strain $19(5 / 19)$ to see if its action was the same as nitrogen mustard. A small quantity of mustard gas was shaken with the basal broth and allowed to stand for $30 \mathrm{~min}$. The broth was then removed and sufficient $19(5 / 19)$ was added to give a bacterial concentration of approximately $25 \times 10^{6}$ bacteria/ml. Incubation was carried out at $37^{\circ}$ for 30 min., the culture centrifuged, the supernatant replaced with an equal volume of basal broth, and incubation continued. Bacterial growth occurred in a similar manner to that obtained with nitrogen mustard. Growth then ceased and lysis occurred with the liberation of large 
Table 6. The induction of phage lysis in lysogenic cultures of salmonellas by exposure to $0.8 \mathrm{mg} . / \mathrm{ml}$. of nitrogen mustard for $30 \mathrm{~min}$.

$\begin{array}{lcc}\text { Culture } & \text { Phage particles, } & 10^{4} / \mathrm{ml} ., \text { liberated } \\ 19(5 / 19) & \text { After induction } & \text { In control culture } \\ 19(1 / 19) & 4,500,000 & 2,100 \\ 2 & 500 & 650 \\ 3 & 3,500,000 & 725 \\ 11 & 3,200,000 & 2,500 \\ \text { C16 } & 1,400,000 & 825 \\ \text { M1 } & 3,500,000 & 3,600 \\ \text { M7 } & 2,500,000 & 8 \cdot 5\end{array}$

The phage counts quoted for the control cultures were those obtained at the stage at which phage induction commenced in the corresponding experimental culture.

Cultures with the prefix ' $C$ ' are $S$. cholerae-suis and those with the prefix ' $M$ ' are $S$. typhimurium; the others are $S$. thompson.

numbers of phage particles. In one experiment the number of free phage particles $/ \mathrm{ml}$. after induction was $75,000 \times 10^{5}$ compared with $50 \times 10^{5}$ in a control culture. As with nitrogen mustard, mustard gas was more lethal to free phage particles than to bacteria.

\section{Colchicine}

Colchicine added to the basal broth in final concentrations of $0 \cdot 001-0 \cdot 1 \%$ had no noticeable effect on the bacterial growth rate of $19(5 / 19)$ and $19(1 / 19)$ or on the number of phage particles liberated.

The liberation of phage particles by strains 2, 8 and $\mathrm{C} 16$ also was not influenced by $0 \cdot 1 \%$ colchicine.

\section{Urethane}

Urethane in concentrations of $0 \cdot 03-3 \%$ was without effect on the liberation of phage particles by $19(5 / 19)$ and $19(1 / 19)$ except at the $3 \%$ level when a marked decrease was noted. The higher concentrations had a pronounced inhibitory effect on the bacterial growth rate. Little or no phage was liberated by seven lysogenic salmonellas grown in broth containing $\mathbf{3} \%$ urethane.

Strains $19(5 / 19)$ and 2 were passaged through broth containing $3 \%$ urethane, each passage taking $24 \mathrm{hr}$. Single colonies obtained by plating out these cultures after fifty passages were all lysogenic.

\section{Sodium citrate}

The lysogenic cultures used in the previous experiments were classified by the citrate sensitivity of the phages they carried. Heat-treated $18 \mathrm{hr}$. broth cultures were titrated for free phage on ordinary nutrient agar with and without $2 \%$ sodium citrate. The phages carried by $19(1 / 19), 8,11$ and M1 were completely sensitive and those carried by strains 2, 3, C11 and C16 were completely insensitive. The phages carried by strains $19(5 / 19)$ and $\mathrm{M} 7$ 
were classified as slightly sensitive since the plaques on citrate-agar were less numerous and smaller than those on ordinary agar.

When the strains were grown in basal broth containing $2 \%$ sodium citrate there was no difference between the amount of free phage liberated than when they were grown in the basal broth alone. The two strains carrying citratesensitive phages, $19(1 / 19)$ and 8 , were passaged through broth containing $2 \%$ sodium citrate, each passage taking 12-24 hr. Single colonies obtained by plating out these cultures after 100 passages were all lysogenic.

\section{The effect of casein digest, yeast extract, methionine, cobalt sulphate, brilliant green, sodium biselenite, sodium taurocholate and sodium tetrathionate}

The following substances when added to the basal broth in the concentrations stated were without any significant effect on the liberation of phage particles by cultures of $19(5 / 19)$ and $19(1 / 19)$ :

$\quad$ Substance
Casein digest (Bacto-Casitone, Difco)
Yeast extract (Oxo)
Methionine
Cobalt sulphate
Brilliant green
Sodium biselenite
Sodium taurocholate
Sodium tetrathionate

Final concentration tested $(\%)$

$0 \cdot 2-1 \cdot 0$

$0 \cdot 3-3 \cdot 0$

$0.025-0.2$

$0.002-0.008$

$0 \cdot 000125-0 \cdot 002$

$0 \cdot 05-0 \cdot 2$

$0 \cdot 05-1 \cdot 0$

0.1-3.0 (approx.)

\section{DISCUSSION}

The results obtained by lysing the bacterial cells of lysogenic strains of $S$. thompson by sodium cyanide and penicillin showed that these cultures resembled other lysogenic cultures; phage was not present within the bacterial cells as infective units capable of producing lysis of susceptible cultures. Williams Smith (1951) observed that it was usually possible to obtain a marked increase in the number of free phage particles liberated by lysogenic cultures of $S$. thompson by producing in them an active infection with another phage. This result was not due to the liberation of phage previously contained within the bacterial cells as infective units. Rather does it suggest that active infection altered the host-parasite relation existing between the bacterial cells and the non-infective phage contained within them thus permitting this phage to become infective and possibly to multiply.

Several views have been put forward to account for the phenomenon of lysogenicity in bacterial cultures. Boyd (1951), working with S. typhimurium, considers that phage exists in two forms and that variation may occur from one form to the other. He postulates that the form existing within the bacterial cell, the symbiotic form, on occasion mutates to the lytic form which lyses the bacterial cell and then constitutes the greater part of the phage that is found free in the culture medium of lysogenic cultures. Lwoff \& Gutman (1950) brought forward the 'activation' hypothesis. They considered that 
the phage existing within the bacterial cell is an incomplete or immature form of lytic phage, called prophage, and that some disturbance of metabolism permits the maturation of some prophage particles, resulting in lysis of the bacterial cell and the presence of free phage in the culture medium. Clarke (1952) and Clarke \& Cowles (1952) are of the opinion that bacteriophage normally exists within the bacterial cell as prophage but that occasionally some bacterial cells within a lysogenic culture revert from the resistant to the sensitive state; this allows the prophage to form active or lytic phage which lyses the cell within which it was contained and becomes free in the culture medium. Much of the evidence for this view depended on the observation (Clarke, 1952) that prolonged passage in calcium-free media eventually resulted in a lysogenic culture of $B$. megaterium becoming non-lysogenic and fully sensitive to the phage it carried previously. It is of interest to consider how the results obtained in this present work accord with these views. They show that the free phage/bacterium ratio in lysogenic cultures of the salmonellas studied was normally a constant one, but that it could be upset by many and quite different chemical and physical stimuli resulting either in a great increase or decrease in the amount of free infective phage present in the culture fluid. In some cases it was noted that different concentrations of the same substance, and even the same concentration at different stages during growth of a culture, had quite opposite effects. Again, subcultures of a strain in which free phage production had been induced by, for example, sodium thiolacetate showed a normal free phage/bacterium ratio when grown in ordinary broth or a great increase in the number of free phage particles if grown again in broth containing sodium thiolacetate. Prolonged passage in citrate broth of lysogenic cultures carrying citrate-sensitive phage, or passage in other media which inhibited production of free phage particles, did not produce cultures that were sensitive to the phage which they had previously carried, as Clarke (1952) had done with the strain of $B$. megaterium. These facts do not support the view that lysogenicity is due either to mutation of phage or bacteria if the term mutation is considered in its most commonly accepted meaning. Rather do they support the view of Lwoff \& Gutman (1950). It is possible then that the phenomenon of lysogenicity in the cultures examined can be explained as follows. When a susceptible bacterial culture is actively infected with phage, the phage particles, after entering the bacterial cells, split up into a number of sub-units. These multiply and then aggregate into the characteristic pattern of fully formed infective particles of the phage from which they were derived, the bacterial cells lyse, and the infective phage particles become free in the culture medium. In some of the bacterial cells this process does not reach completion and a state of equilibrium is established between phage and bacterial cell. The stage of phage development at which equilibrium is reached would be somewhere between the stage at which multiplication of the sub-units was possible, since bacterial cells resulting from multiplication of latently infected cells contain phage which is able to become infective, and the stage when they coalesce and also become infective. These are the bacterial cells that constitute a 
lysogenic culture. The host-parasite relation is not stable; occasionally it is upset in some cells so as to permit the formation of infective phage which lyses the cells and can be demonstrated in the culture medium. Since most studies on bacteriophage have been concerned with the active infection of susceptible bacterial cells, too much emphasis has been placed on this type of relation. It is probable that in nature the normal relation between bacterium and phage is that found in lysogenic cultures and that active infection is relatively a rare event. It might therefore be inadvisable to refer to phage in its normal state in the bacterial cell as immature or as prophage; it is suggested that these terms should not be used but instead the term noninfective be used.

Lwoff et al. (1950), Lwoff \& Siminovitch (1951) found that the induction of phage lysis by means of reducing agents was dependent on the type of culture media used and they classified media accordingly as 'active' and 'inactive'. They found that broth was inactive for the strain of B. megaterium with which they were working. Lwoff (1952) discovered that the ability to bring about phage induction was dependent on the cationic balance of the medium and found that copper favoured induction by reducing agents and that cobalt was antagonistic to it. He showed that the concentration of thiolacetate necessary to induce lysis was indirectly related to the amount of copper present and directly to the amount of cobalt present. A different position existed in the salmonella cultures I examined. Broth was quite a satisfactory medium to demonstrate inducing effects, copper and cobalt played no part in thiolacetate induction, and of the reducing agents tested only those containing SH groups, sodium thiolacetate and glutathione, were able to induce phage lysis. The method of induction by thiolacetate and glutathione cannot be explained simply by alteration in the $\mathrm{eH}$ of the medium since it could not be obtained by all reducing agents. However, it was dependent on the amount of thiolacetate present and on the $\mathrm{eH}$ of the medium in some way since the inducing effects were not obtained in anaerobic cultures, although anaerobiosis had no effect on the liberation of free phage by cultures growing in ordinary broth. It was noted, too, that the higher concentrations of thiolacetate often caused some induction of lysis in the earlier stages of the growth cycle, followed by inhibition of phage production later; this inhibition was also noted with ascorbic acid.

Substances such as proflavine, cobalt sulphate, and yeast extracts were examined in the hope that they might throw light on the part played by nucleic acids in phage production, but the results were negative. Sulphathiazole was the only chemotherapeutic agent studied that had any effect on the liberation of phage particles and, since the increase did not occur when $p$-aminobenzoic acid was added, or when a large bacterial inoculum was used, it seemed that the increased liberation of phage might be associated with the bacteriostatic action of the sulphonamides, i.e. by interfering with $p$-aminobenzoic acid metabolism. Since many phenomena are common to both bacterial and animal virus systems it is tempting to compare the effect of sulphathiazole on lysogenic bacteria with the clinical observation that the 
administration of sulphonamides in some animal virus infections, e.g. canine distemper, may result in an exacerbation of clinical symptoms. It is probable, however, that this is taking the comparison a little too far.

Nitrogen mustard and mustard gas induced lysis in lysogenic cultures in a similar manner to ultraviolet and X-rays; this is another reason for considering that the general biological activity of the mustards closely resembles that of ultraviolet and X-rays. It is noteworthy that of all the substances tested nitrogen mustard and mustard gas were the only two that were lethal to free phage particles in concentrations that were not lethal to bacteria. They were, however, able to stimulate the formation of very large amounts of free phage if they were removed from the medium after they had been in contact with the bacteria for a period of time or to a lesser extent when concentrations which were not lethal to free phage were added to the medium. The induction of phage lysis by means of nitrogen mustard, too, appears not to be restricted to the salmonellas since Jacob (personal communication) has independently and simultaneously discovered that it also induces the same effect in Pseudomonas pyocyanea.

I am indebted to Miss J. M. Gavins for her excellent technical help and to Mr L. D. S. Williams for a supply of mustard gas.

\section{REFERENCES}

Bertani, G. (1951). Studies on lysogenesis. 1. The mode of phage liberation by lysogenic Escherichia coli. J. Bact. 62, 293.

BoyD, J. S. K. (1951). Observations on the relationship of symbiotic and lytic bacteriophage. J. Path. Bact. 63, 445.

Cavallo, G. (1951). Induction de la lyse bactériophagique de microbes lysogènes par le 'shock' thermique. C.R. Soc. Biol., Paris, 145, 1885.

Cavallo, G. \& Cantelio, P. (1951). Induction par les rayons ultraviolet de la lyse bactériophagique des staphylocoques lysogènes. C.R. Soc. Biol., Paris, $145,1419$.

Clarke, N. A. (1952). Studies on the host-virus relationship in a lysogenic strain of Bacillus megaterium. II. The growth of Bacillus megaterium in a synthetic: medium. J. Bact. 63, 187.

Clarke, N. A. \& Cowles, P. B. (1952). Studies on the host-virus relationship in a lysogenic strain of Bacillus megaterium. 1. The relationship between growth and bacteriophage production in cultures of Bacillus megaterium. J. Bact. 63,177 .

Ionesco, H. (1952). C.R. Acad. Sci., Paris (in the Press). Quoted by $\mathrm{J}_{\mathrm{ACOB}}$, F. (1952). Ann. Inst. Pasteur. 82, 433.

$\mathrm{J}_{\mathrm{ACOB}}, \mathrm{F}$. (1950). Induction de la lyse et de la production de bactériophage chez un Pseudomonas pyocyanea lysogène. C.R. Acad. Sci., Paris, 231, 1585.

LATARJET, R. (1951). Induction, par les rayons $X$, de la production d'un bactériophage chez B. megaterium lysogène. Ann. Inst. Pasteur, 81, 389.

Lwoff, A. (1952). Rôle des cations bivalents dans l'induction du développement du prophage par les agents réducteurs. C.R. Acad. Sci., Paris, 234, 366.

Lwoff, A. \& Gutman, A. (1950). Recherches sur un Bacillus megaterium lysogène. Ann. Inst. Pasteur, 78, 711.

Lwoff, A. \& Siminovitch, L. (1951). Induction par des substances réductrices de la production de bacteriophage chez un bactérie lysogène. C.R. Acad. Sci., Paris, 231, 190. 
Lwoff, A., Siminovitch, L. \& KJeldgaARd, N. (1950). Induction de la production de bactériophages chez un bactérie lysogène. Ann. Inst. Pasteur, 79, 815.

Miles, A. A. \& Misra, S. S. (1938). The estimation of the bactericidal power of the blood. J. Hyg., Camb. 46, 82.

Quersin, L. (1951). Lyse induite du bacille lysogène de Lisbonne. C.R. Soc. Biol., Paris, 145, 1425.

Rountree, P. M. (1951). A complement-fixing antigen of B. coli bacteriophage T5: its behaviour during virus growth. Brit. J. exp. Path. 32, 341.

Weigle, J. J. \& Delbrück, M. (1951). Mutual exclusion between an infecting phage and a carried phage. J. Bact. 62, 301.

Wilitams Smith, H. (1951). Some observations on lysogenic strains of Salmonella. J. gen. Microbiol. 5, 458.

(Received 12 July 1952) 